\title{
Real-Time Laser Doppler Imaging as a Prognostic Tool in Frostbite Injuries of the Upper Extremity
}

\author{
Marwan Hardan ${ }^{1 *}$ and Wassim Raffoul ${ }^{2}$ \\ ${ }^{1}$ Hand surgeon, Department of trauma and orthopedics surgery, Neuchâtel Hospital, Switzerland \\ ${ }^{2}$ Chief of Department of Plastic, Reconstructive and Aesthetic Surgery, University Hospital of Lausanne (CHUV), Switzerland
}

*Corresponding author: Marwan Hardan, Department of trauma and orthopedics surgery, Neuchâtel Hospital, Switzerland.

\begin{abstract}
Cold-induced lesions, better known as frostbite lesions, are the result of prolonged exposure of the skin to a low temperature. Various efforts have been made to stage these lesions and to provide early prognostic information, of which Cauchy's classification, using clinical information and technetium bone scanning at day 7, is widely accepted. Recently, Laser Doppler imaging (LDI) has been proposed as a valuable method in the quantification of (micro) perfusion of tissues in burn victims and in the surveillance of free flaps. LDI may also be a valuable prognostic tool in the treatment of frostbite lesions. In this case report, we present the use of LDI in the treatment of a 42-year old patient suffering from frostbite injuries to both hands.
\end{abstract}

\section{Introduction}

Cold-induced lesions, better known as frostbite lesions, are the result of prolonged exposure of the skin to a low temperature. The severity of frostbite lesions depends on various factors, most importantly to the length of exposure, the outside temperature and the level of protection used. These types of injuries are mostly found on the hands, feet, ears and nose, and may lead to necrosis of the affected extremity [1-3]. The accepted classification was created by Cauchy et al. in 2001, based on their experience as a referral center in the French Alps. This classification, as depicted in Table 1 , provides a clinical tool to aid the surgeon in the decision of the type of surgical treatment needed, based on clinical examination and technetium bone scanning at day 2 and 7. This tool may provide a reliable prognostic value after day 7 , necessitating treatment delay until after this time period [4-6].Real-time laser Doppler imaging (LDI), is known to be a viable monitoring tool for the postoperative surveillance of microvascular anastomoses and free flaps [7]. In a recent study on 15 burn patients, LDI significantly improved accuracy of burn depth assessment compared to the clinical judgement performed by experienced surgeons (93\% vs $80 \%$ of correctly assessed burn depth, $\mathrm{p}<0.05$ ) [8]. LDI may also be a valuable prognostic tool in the treatment of frostbite lesions. In this case report, we present the use of LDI in the treatment of a patient suffering from frostbite injuries to both hands.

Table 1: Cauchy classification scheme for severity of frostbite injuries (adapted from: Cauchy et al. Wilderness and Environmental Medicine, 12, 248255 [2].

\begin{tabular}{|c|c|c|c|c|}
\hline Frostbite Injuries of the Extremities & Grade 1 & Grade 2 & Grade 3 & Grade 4 \\
\hline $\begin{array}{c}\text { Extent of initial lesion at day } 0 \text { after } \\
\text { rapid rewarming }\end{array}$ & $\begin{array}{l}\text { Absence of } \\
\text { initial lesion }\end{array}$ & $\begin{array}{l}\text { Initial lesion on distal } \\
\text { phalanx }\end{array}$ & $\begin{array}{l}\text { Initial lesion on intermediary } \\
\text { (and) proximal phalanx }\end{array}$ & Initial lesion on carpal/ tarsal \\
\hline Bone scanning at day 2 & Useless & $\begin{array}{c}\text { Hypo fixation of radiotracer } \\
\text { uptake area }\end{array}$ & $\begin{array}{l}\text { Absence of radiotracer up- } \\
\text { take area on the digit }\end{array}$ & $\begin{array}{l}\text { Absence of radiotracer uptake } \\
\text { area on the carpal/tarsal }\end{array}$ \\
\hline Blisters at day 2 & $\begin{array}{l}\text { Absence of } \\
\text { blisters }\end{array}$ & Clear blisters & $\begin{array}{l}\text { Hemorrhagic blisters on the } \\
\text { digit }\end{array}$ & $\begin{array}{l}\text { Hemorrhagic blisters over } \\
\text { carpal/tarsal }\end{array}$ \\
\hline Prognosis at day 2 & $\begin{array}{l}\text { No amputa- } \\
\text { tion }\end{array}$ & Tissue amputation & Bone amputation of digit & $\begin{array}{l}\text { Bone amputation of the limb / } \\
\text { systemic involvement / sepsis }\end{array}$ \\
\hline Sequelae & No sequelae & Fingernail sequelae & Functional sequelae & Functional sequelae \\
\hline
\end{tabular}




\section{Case Description}

We report on a 42-year old right-handed, non-smoking, male without any relevant patient history. The patient was exposed to temperatures between -5 and $-15^{\circ} \mathrm{C}$ during a half-day hike in the Swiss Alps. Upon removal of his gloves both hands showed signs of frostbite injury: a dark blue-gray color of the distal phalanges of fingers $2-5$ on the right hand and fingers 3-5 on the left hand (Figure1). Initially no dysesthesia or pain was noted. The patient presented to a nearby general emergency department within 30 minutes after removal of the gloves, where $1 \mathrm{~g}$ of Acetylsalicylic acid and $1 \mathrm{~g}$ of paracetamol were administered orally. The hands were submerged in a $40^{\circ} \mathrm{C}$ water bath for 15 minutes, after which the patient was transferred to our specialized center. Upon arrival at our center, the patient reported a pain score of $10 / 10$ on the visual analog scale. Clinically, there was an anesthesia of the distal phalanges without signs of infection or cutaneous defects. Initially, the hands were submerged in a $40^{\circ} \mathrm{C}$ sterile Betadine-NaCL solution for 30 minutes. Pain was controlled by tramadol. Based on the abovementioned Cauchy [2] classification, the initial survey concluded that the patient suffered from stage 2 and 3 frostbite lesions on both hands. The patient was transferred to a continuous care facility for further treatment, which consisted of an IV drip with $25.2 \mu \mathrm{g}$ of Ilomedine on day 0 and $50.42 \mu \mathrm{g}$ in the days that followed. Thrombosis prophylaxis, recommended with Ilomedine use, was given in the form of $40 \mathrm{mg}$ of Enoxaparine subcutaneously. Oral antalgics and anti-aggregation by Acetylsalicylic acid were continued. Daily betadine baths (30 minutes, at $40^{\circ} \mathrm{C}$ ) and debridement of phlycten were performed, after which a silversulfadiazine (Ialugen-plus(C) crème was applied. On day 4, after delimitation of finger necrosis, Ilomedine was stopped and the patient transferred to a conventional surgical ward, where local wound care and symptomatic therapy was continued until day 9 . Furthermore, ergotherapy, physical therapy and Vibradol treatment was performed. Vascular surveillance of the affected digits was carried out by laser Doppler flowmetry (LDI). Measurements were taken at day 4, 5 and 7 during hospitalization (Figure 1), and continued regularly in the outpatient clinic until 1-year post-exposure, with a final measurement at 2 years. All fingers eventually showed complete remission of clinical symptoms and LDI endpoints, at various time points (Table 2).

Table 2: Initial clinical staging and LDI results at day 4.

\begin{tabular}{|c|c|c|c|c|}
\hline Finger & $\begin{array}{c}\text { Initial Cauchy } \\
\text { Score }\end{array}$ & APU Day 4 & $\begin{array}{c}\text { Time to } \\
\text { remission }\end{array}$ & Skin color \\
\hline \multicolumn{5}{|c|}{ Left hand } \\
\hline 2,5 & I & $300 \%$ & 3 days & Dark Red \\
\hline 3 & II & $205 \%$ & 2 months & Red \\
\hline \multicolumn{5}{|c|}{ Right hand } \\
\hline 4 & II & $300 \%$ & 3 weeks & Dark Red \\
\hline 5 & II & $165 \%$ & 4 months & Light Red \\
\hline 2 & II & $140 \%$ & 6 months & Light Red \\
\hline 3 & III & $65 \%$ & 1 year & Black Purple \\
\hline
\end{tabular}

\section{Laser Doppler Imaging (LDI)}
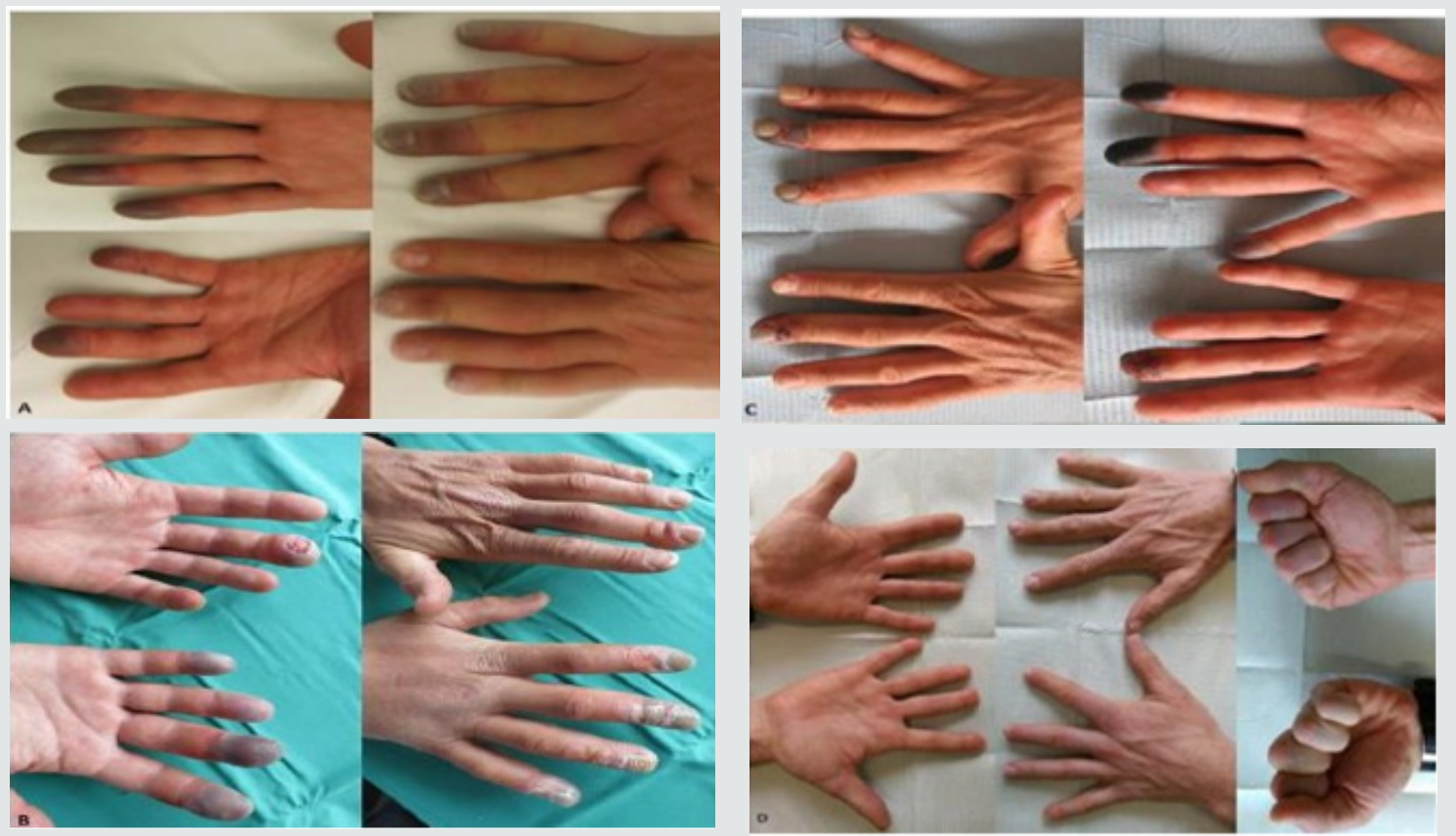

Figure 1: Clinical aspect of the hands at day 0 (Figure 4(A)), at day 4 (Figure 4(B), at day 9 (Figure 4(C)) and at 2 years (Figure 4(D)). 
The principle of LDI is based on the Doppler effect of a laser beam that is used to calculate volumetric blood flow. The laser beam is emitted towards a tissue surface, which penetrates the skin at a mean depth of $2 \mathrm{~mm}$. The speed of the erythrocytes moving within the capillary scatters the laser beam and shifts the wavelength. The extent of the shift correlates with the speed of the moving erythrocytes, and the changes in wavelength represent the number of erythrocytes in the sampled tissue. This data is then used to calculate the volumetric blood flow, expressed as arbitrary perfusion units (APU). The LDI system we used (FluxEXPLORER, Aimago, Lausanne, $\mathrm{CH}$ ) is a novel combined LDI technique, which provided an increased measurement area and speed. It provided microcirculatory blood flow cartography of an area of $9 \times 9 \mathrm{~cm}$ with a resolution of $256 \times 256$ pixels in 1 s. In the current case, all measurements were done following the same measurement protocol, in order to minimize inter-observer variability. Measurements were taken at ambient temperature between 28- 32 degrees. The distance from the laser source to the skin was 15-20 $\mathrm{cm}$ and placed perpendicular to the hand (Figure 1). No protective eyewear was needed for this type of laser emitting technology.

\section{Discussion}

Frostbite lesions generally affect the extremities, mostly the hands and feet. Their severity depends on the length of exposition, the outside temperature and weather conditions and protective gear used. Frostbite lesions lead to soft tissue damage by the direct effect of freezing and thawing, as well as by vasospasm and arterial thrombosis. Healing depends on the restoration of the local microvascularisation and the capacity of vasodilatation, failure of which leads to gangrene and eventually amputation [9]. Treatment consists of re-heating the affected tissue in saline solution of 38$40^{\circ} \mathrm{C}$, increasing the core temperature by drinking heated fluids or a heated iv-drip and protective clothing. After first-aid measures are applied, inpatient treatment consists of regular surgical debridement and medical treatment by Aspirin, Buflomedil, Prostacyclin, Tissue plasminogen activator and Iloprost, which increase vascular perfusion locally. Out of these treatments, none have been validated scientifically, and various guidelines exist depending on region and physician preference [10-13]. Early prognosis of frostbite lesions is difficult as lesions tend to take several weeks to delimit themselves, hence the well-known dogma 'Frozen in January, amputated in June' [14]. In fact, the initial clinical presentation has been shown to account for only around $30 \%$ of the final delimited soft tissue damage [3]. Several techniques have been proposed as early staging exams. Thermography, Capillaroscopy and angiography have not shown conclusive results. X-rays offer little to no information in the acute stage, as bone lesions only tend to become evident after several weeks [15]. Magnetic resonance imaging (MRI) has been proposed as an early staging exam and may provide information on tissue vitality and arterial occlusion, however, has not been shown to correlate with clinical amputation level [16]. Furthermore, the role of Technetium-99m scintigraphy has been reported to be a valuable staging tool.
In Cauchy's staging system, Te-99m scintigraphy is used at day 2 and 7, providing a valuable prognostic tool, aiding in choosing amputation level after Day 7 [3]. Despite its value, Te$99 \mathrm{~m}$ scintigraphy remains an expensive tool, necessitating the use of radioactive material. Furthermore, the presence of phlycten may disturb the measurements. Laser Doppler imaging (LDI) is a non-invasive, low-cost technique, well-known in Plastic surgery for the surveillance of free flaps and in burn victims [7-8]. A recent randomized control trial including 202 patients from various Dutch burn centers used LDI to aid in burn staging, optimizing treatment timing. By identifying patients in need of surgery earlier the authors reported an amelioration in patient outcomes and a decrease in healthcare costs [17]. In another study, LDI was used to evaluate 148 burns in 115 patients and was reported to be useful in quantifying burn depth, showing a correlation between vascular micro perfusion and burn depth [18]. In our case, LDI on day 4, 5 and 7 showed the evolution of APU results and variations in color cartography, while clinical signs (i.e. aspect of the skin) remained stable. APU results correlated directly to prognosis, in terms of time to remission and final clinical aspect [19-22]. This finding may be important, as Cauchy stage 2 or 3 frostbite lesions with acceptable APU results may enable conservative treatment without early amputation [23-28].

\section{Conclusion}

Laser Doppler Imaging is an easy to use, low-cost technique that provides a real time image and staging of microvascular perfusion without the risk of contamination or radioactivity [29-32]. This technology may play an important part in the treatment protocol of frostbite lesions, possibly reducing prognostic delay and optimizing treatment strategies [33-41]. We call for further research on this subject before definitive conclusions can be made.

\section{References}

1. Koljonen V, Andersson K, Mikkonen K, Vuola J (2004) Frostbite Injuries Treated in the Helsinki Area from 1995 to 2002. The Journal of TRAUMA Injury, Infection and Critical Care 57(6): 1315-1320.

2. Miller BJ, Chasmar LR (1980) Frostbite in Saskatoon: A Review of 10 winters. The Canadian Journal of Surgery 23(5): 423-426.

3. Emsen IM (2007) A dangerous sequele of frostbite: Third-degree ear burn. J Burn Care Res 28 (3): 539.

4. Cauchy E, Marsigny B, Allael G, Verhellen R, Chetaille E (2000) The value of Technetium 99 scintrigraphy in the prognosis of amputation in severe frostbite injuries of the extremities: a retrospective study of 92 severe frostbite injuries. J Hand Surg 25(5): 969-978.

5. Cauchy E, Chetaille E, Lefevre M, Kerelou E, Marsigny B (2000) The role of bone scanning in severe frostbite of the extremities: a retrospective study of 88 cases. Eur J Nucl Med 27(5): 497-502.

6. Cauchy, Chetaille E, Marchaud V, Marsigny B (2001) Retrospective study of 70 cases of severe frostbite lesions: a proposed new classification scheme. Wilderness and Environmental Medicine 12(4): 248-255.

7. Tschumic C, Jafari MS, Rothenberger J, Van de ville D, Keel M, et al. (2015) Post-operative monitoring of free muscle transfers by Laser Doppler Imaging: A restrospective study. Microsurgery 35(7): 528-535. 
8. Erba P, Espinoza D, Koch N, Christen T, Serov A, et al. (2012) FluxEXPLORER: a new high-speed laser Doppler imaging system for the assessment of burn injuries. Skin Research and Technology 18(4): 456-461.

9. Bhatnagar A, Sarker B B, Sawroop K, Chopra M K, Sinha N, et al. (2002) Diagnosis, characterisation and evaluation of treatment response of frostbite using pertehnetate scintigraphy: a prospective study. Eur J Nucl Med 29(2): 170-175.

10. Sharikaya I, Cemal Aygit A, Candan L, Sarikaya A, Türkyilmaz M, et al. (2000) Assessment of tissue viability after frostbite injury by technetium-99m-sestamibi scintigraphy in an experimental rabbit model. Eur J Nucl Med $27: 41-45$

11. Johnson AR, Jensen HL, Peltier G, DelaCruz E (2011) Efficacy of Intravenous Tissue Plasminogen Activator in Frostbite Patients and Presentation of Treatement Protocol for Frostbite Patients. Foot Ankle Spec 4(6): 344-348.

12. Wagner W, Pannucci CJ (2011) Thrombolytic Therapy in the Acute Management of Frostbite Injuries. Air Medical Journal 30(1): 39-44.

13. Groechenig E (1994) Treatment of frostbite with iloprost. The Lancet 344(8930): 1152-1153.

14. Foray J (1992) Mountain Frostbite Current Trends in Prognosis and Treatment (from results concerning 1261cases). TNT J Sports Med 13(1): S193-S196.

15. Heggers JP, Robson MC, Manavalen K, Weingarten MD, Carethers JM, et al. (1987) Experimental and clinical observations on frostbite. Ann Emerg Med 16: 1052-1062.

16. Barker JR, Haws MJ, Brown RE, Kucan JO, Moore WD (1997) Magnetic resonance imaging of sever frostbite injuries. Ann Plast Surg 38(3): 275279.

17. Hop M J, Stekelenburg CM, Hiddingh J, Kuipers HC, Middelkoop E, et al (2015) Cost-Effectiveness of Laser Doppler Imaging in Burn Care in The Netherlands: A Randomized Controlled Trial. Plastic and reconstructive surgery journal 137(1): 166e-176e.

18. Stetinsky J, Klosova H, Kolarova H, Salounova D, Bryjova I, et al. (2015) The Time Factor in the LDI (Laser Doppler Imaging) Diagnosis of Burns. Lasers Surg. Med 47(2): 196-202.

19. Leutenegger M, Martin Williams E, Harbi P, Thacher T, Raffoul W, et al (2011) Real-time full field laser Doppler imaging. Biomedical Optics Express 2(6): 1470-1477.

20. Hutchison Richard L (2014) Frostbite of the Hand. J Hand Surg Am 39(9): 1863-1868.

21. Burke Smith A, Collier J, Jones I (2015) A comparison of non-invasive imaging modalities: Infrared thermography, spectrophotometric intracutaneous analysis and laser Doppler imaging for the assessment of adult burns. Burns 41(8): 1695-1707.

22. Bruen KJ, Ballard JR, Morris SE, Cochran A, Edelman LS, et al. (2007) Reduction of the Incidence of Amputation in Frostbite Injury with Thrombolytic Therapy. Arch Surg 142: 546-553.

23. Ahmad Z (2013) Managing frostbite in a South African patient. Int Wound J 10(4): 480-481.
24. Zafren K (2013) Frostbite: Prevention and Initial Management. High Altitude Medicine \& Biology 14(1): 9-12.

25. Ingram BJ, Raymond TJ (2013) Recognition and Treatment of Freezing and Nonfreezing Cold Injuries. Current Sports Medicine Reports 12(2): 125-130.

26. Twomey JA, Peltier GL, Zera RT (2005) An Open-Label Study to Evaluate the Safety and Efficacy of Tissue Plasminogen Activator in Treatment of Severe Frostbite. J Trauma 59(6): 1350-1355.

27. Vogel JE, Dellon L (1989) Frostebite injury of the Hand. Clinics in plastic surgery $16(3)$

28. Bruen KJ, Gowski WF (2009) Treatment of Digital Frostbite: Current Concepts. Jhsa 34(3): 553-554.

29. Su CW, Lohman R, Gottleib L (2000) Frostbite of The Upper Extremity. Hand Clinics 16(2):235-247.

30. Roche Nagle G, Murphy D, Collins A, Sheehan S (2008) Frostbite: management options. European Journal of Emergency Medicine 15(3): 173175 .

31. Handford C, Buxton P, Russell K, Imray C EA, McIntosh SE, et al. (2014) Frostbite: a practical approach to hospital Management. Extreme Physiology \& Medicine 3: 1-7.

32. Valnicek SM, Chasmar LR, Clapson JB (1992) Frostbite ine The Parairies: A 12 Years Review. Palstic and Reconstructive Surgery 92(4): 633-641.

33. Pulla RJ, Pickard LJ, Carnett TS (1994) Frostbite: An Overview with Case Presentations. The Journal of Foot and Ankle Surgery 33(1): 53-63.

34. Golant A, Nord RM, Paksima N, Martin A (2008) Posner MA Cold Exposure Injuries to the Extremities. J Am Acad Orthop Surg 16(2): 704-715.

35. Bilgiç S, Özkan H, Özenç S, Safaz I, Yildiz C (2008) Treating frostbite. Can Fam Physician 54: 361-363.

36. Cauchy E, Cheguillaume B, Chetaille E (2011) A Controlled Trial of a Prostacyclin and rt-PA in the Treatment of Severe Frostbite. The New England Journal of Medicine 364(2):189-190.

37. Graham CA, Stevenson J (2000) Frozen chips: an unusual cause of severe frostbite Injury. Br J Sports Med 34: 382-384.

38. Hassi J, Mäkinen TM (2000) Frostbite: Occurrence, Risk Factors and Consequences. International Journal of Circumpolar Health 59: 92-98.

39. Robson MC, Hegger JP (1981) Evaluation of Hand Blister Fluid as a Clue to Pathogenesis. Am JHS 6(1): 43-47.

40. Carpenter HM, Hurley LA, Hardenbergh E, Williams B (1971) Vascular Injury Due to Cold. Affects of Rapid Rewarming. Arch Path 92(3): 1531561.

41. Chandran GJ, Chung B, Lalonde J, Lalonde DH (2010) The Hyperthermic Effect of a Distal Volar Forearm Nerve Block: A Possible Treatment of Acute Digital Frostbite Injuries? Plastic and Reconstructive Surgery 126(3): 946-950. 
CC (i) This work is licensed under Creative Commons Attribution 4.0 License

To Submit Your Article Click Here: Submit Article

DOI: $10.32474 /$ RRHOAJ.2019.04.000185

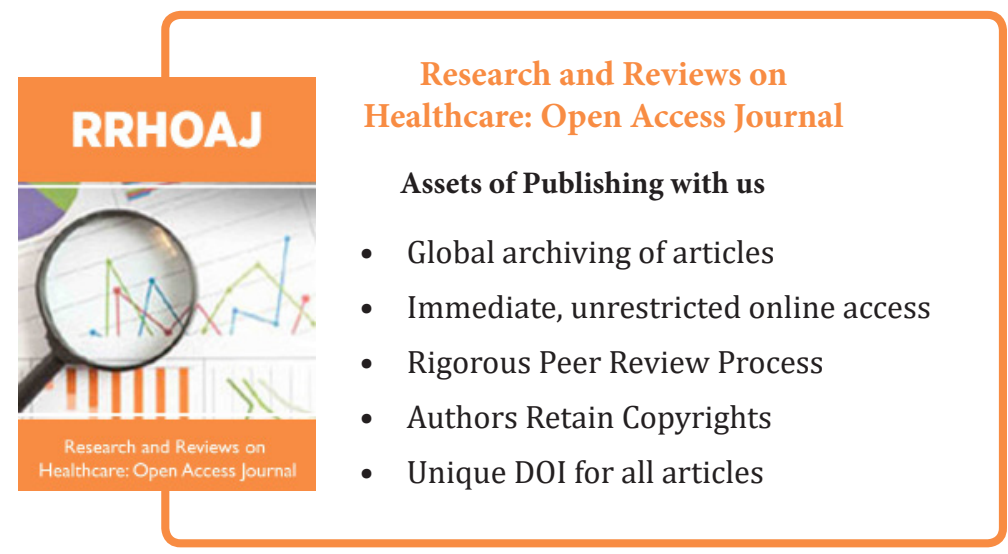

